\title{
A non-isotopic in situ hybridisation study of the chromosomal origin of 15 supernumerary marker chromosomes in man
}

\author{
J A Crolla, N R Dennis, P A Jacobs
}

\begin{abstract}
Fifteen patients presenting with mosaic or non-mosaic karyotypes containing a distamycin-DAPI negative de novo or familial supernumerary marker chromosome were studied with non-isotopic in situ hybridisation using a library of alphoid centromere specific and satellite II/III probes. The in situ hybridisation studies showed that seven markers were derived from satellited autosomes (three chromosome 13/21, two chromosome 14, two chromosome 22), six from non-satellited autosomes (two chromosome 4, one chromosome 12 , one chromosome 16 , two chromosome 19), and one from the $Y$ chromosome. One non-mosaic marker was negative for all the alphoid and satellite II/III probes used. ( $\mathcal{F}$ Med Genet 1992;29:699-703)
\end{abstract}

Supernumerary marker chromosomes are found in approximately $2 \cdot 0 / 1000$ pregnancies studied for prenatal diagnosis ${ }^{1}$ and in $0 \cdot 3 / 1000$ newborns. ${ }^{2}$ The frequency of de novo markers increases with maternal age, ${ }^{3}$ thus accounting for their high incidence among amniocentesis specimens, most of which are referred for this reason. By excluding patients presenting with cytogenetically definable markers such as $\mathrm{i}(12 \mathrm{p})$ and $\mathrm{i}(18 \mathrm{p}$ ) (see Discussion), a recent multicentre study ${ }^{4}$ has calculated that the incidence of de novo supernumerary markers not identifiable using standard cytogenetic techniques is $1 / 2500$ amniocenteses with satellited and non-satellited markers occurring with approximately equal frequencies.

The phenotypic risks, both intellectual and physical, conferred by the presence of a supernumerary marker have always been difficult to predict owing to the paucity of long term clinical follow up data from such cases. As a result, published risk estimates are given with large margins of error. ${ }^{14}$ This dilemma is at its most acute when a de novo marker is found prenatally.

A recent study by Warburton ${ }^{4}$ on a series of 377353 amniocenteses carried out in the United States and Canada over a 10 year period calculated the risk of an abnormal phenotypic outcome in cases of de novo markers to be approximately $13 \%$ and, unlike previous studies, ${ }^{1}$ found no significant difference in the risk conferred by a satellited compared with a non-satellited marker chromosome.

These estimates, however, do not take into account the chromosomal origin of the marker which until recently has been impossible to determine. An exception has been those markers with distamycin-DAPI staining properties by which they are assumed to be derived from chromosome 15 . The majority of de novo duplicated distamycin-DAPI staining markers formed from regions including 15 pter $\rightarrow$ q12 are associated with mental impairment varying from mild to very severe. ${ }^{5-7}$

The isolation and cloning of centromere specific alphoid sequences, ${ }^{89}$ together with the development of non-isotopic in situ hybridisation techniques, have made it possible to identify the chromosomal origin of supernumerary marker chromosomes rapidly and systematically. The first reports used probes isolated from the alphoid sequences of the $\mathrm{X}$ and $\mathrm{Y}$ chromosomes to determine the origin of marker chromosomes in patients with Turner's syndrome. ${ }^{10-12}$ More recently, studies using autosomal centromere specific probes have identified the chromosomal origin of 13 small ring chromosomes. ${ }^{1314}$

We have studied 15 supernumerary marker chromosomes, both familial and de novo, and have determined the chromosomal origin of 14. The phenotypes of 12 of the 15 patients are described in the light of the chromosomal origin of the markers.

\section{Materials and methods}

Non-isotopic in situ hybridisation was performed on conventional cytogenetic preparations, usually within 48 hours of making the slides. The in situ hybridisation method used is described in detail elsewhere. ${ }^{15}$ Briefly, biotinylated probe DNA (Biotin-16-dUTP, Boehringer Mannheim) was used at a final concentration of 0.5 to $2 \mathrm{ng} \mathrm{DNA} / \mu \mathrm{l}$ of hybridisation mixture $(50 \%$ formamide with $10 \% \mathrm{w} / \mathrm{v}$ dextran sulphate, $2 \times \mathrm{SSC}$, and $1 / 20$ vol of sonicated carrier herring sperm DNA). Hybridisation was carried out overnight at 42 to $45^{\circ} \mathrm{C}$ and after stringent washing (usually $0.2 \times \mathrm{SSC} / 50 \%$ formamide at $37^{\circ} \mathrm{C}$ for $40 \mathrm{mi}-$ nutes) the sites of hybridisation were detected using either an indirect immunoperoxidase staining method, or fluorescent in situ hybridisation (FISH) following the protocol of Kievits et al. ${ }^{16}$

The library of probes used is listed in table 1 , from which it can be seen that all centromeres could be individually identified with the exception of 5 and 19, and 13 and 21 . In each experiment, the labelling of the normal homologues acted as an internal control and the marker was scored positive for a probe only if 
Table 1 Probes used.

\begin{tabular}{llll}
\hline Chromosome & Region & Probe & Locus \\
\hline 1 & Cen & pSD1.1 & $D 1 Z 5$ \\
$2 / 20$ & Cen & pBS4D & - \\
3 & Cen & p23.5 & $D 3 Z 1$ \\
4 & Cen & ONCOR & $D 4 Z 1$ \\
$5 / 1 / 19$ & Cen & ONCOR & $D 5 / 1 / 19 / Z 1$ \\
6 & Cen & ONCOR & $D 6 Z 1$ \\
7 & Cen & p7t1 & $D 7 Z 1$ \\
8 & Cen & pJm128 & $D 8 Z 2$ \\
9 & Cen & pMR9A & - \\
9 & qh & pHuR98 & $D 9 Z 3$ \\
10 & Cen & p $10 R P 8$ & $D 10 Z 1$ \\
11 & Cen & pLC11A & $D 11 Z 1$ \\
12 & Cen & p $12 H 8$ & - \\
$13 / 21$ & Cen & LI.26 & $D 13 Z 1$ \\
$14 / 22$ & Cen & p14.1 & - \\
15 & Cen & pTRA20 & - \\
16 & Cen & pSE16 & $D 16 Z 2$ \\
16 & qh & pHuR195 & $D 16 Z 3$ \\
17 & Cen & p17H8 & $D 17 Z 1$ \\
18 & Cen & LI.84 & $D 18 Z 1$ \\
20 & Cen & p3.4 & $D 20 Z 1$ \\
$21 / 13$ & Cen & LI.26 & $D 13 Z 1$ \\
22 & Cen & p190.22 & $-\overline{1}$ \\
X & Cen & pSV2X5 & $D X Z 2$ \\
Y & Cen & Y84 & $D Y Z 3$ \\
Y & p & Y-190 & $D Y Z 5$ \\
\hline
\end{tabular}

the normal homologues and the marker were labelled in at least three metaphases. This was particularly important with very small markers where slight increases of background labelling sometimes gave a false positive signal in single cells. One probe was used per slide and the library systematically applied until the chromosomal assignment was made. In cases 10 and 11 , the marker chromosomes hybridised strongly with the probe D5/1/19Z1. Chromosome 1 was excluded by negative signal with $\mathrm{D} 1 \mathrm{Z1}$, and chromosome 19 was selected after a positive signal was obtained in both cases with D16Z2 which, at low stringency, cross hybridises with chromosomes $1,4,9,16$, and 19. As the chromosome 5 centromere did not stain with $\mathrm{D} 16 \mathrm{Z} 2$ under these conditions, it was assumed that the markers were of 19 origin.

Analysis was carried out using a Carl Zeiss Axiophott microscope equipped with epifluorescence and FITC filter combination 09. Photographs were taken using Kodak P800/1600 push process transparency film.

\section{Results}

In 12 of the 15 cases examined, the supernumerary marker was de novo, two were inherited from the mother, and the status of the remaining marker could not be ascertained (table 2). The chromosomal origin in 14 of the 15 markers was resolved and in one case no signal was seen after hybridisation with all probes listed in table 1 . Descriptions of the karyotypes and patients are given below.

CASE 1: 46,XX/47,XX, + MAR(4)MAT

Amniocentesis on a 38 year old woman showed a very small $(<22)$ marker in $80 \%$ of amniocytes. The same marker was found in $70 \%$ of lymphocytes from the clinically normal mother. In situ diagnosis was performed on the fetal amniocytes, from which the marker was eventually lost in vitro. The pregnancy ended spontaneously at 32 weeks with a breech delivery of a phenotypically normal female. Nine months after birth, the baby was developing normally.

CASE 2: $46, \mathrm{XX} / 47, \mathrm{XX},+\operatorname{MAR}(4) \mathrm{DE}$ NOVO

Amniocentesis on a 37 year old woman showed a very small $(<22)$ marker in $27 \%$ of amniocytes. The pregnancy was terminated and the presence of the marker confirmed in fetal tissues. No clinical details of the fetus were available.

CASE 3: $46, \mathrm{XX} / 47, \mathrm{XX},+\operatorname{MAR}(12)$ DE NOVO

A very small marker $(<22)$ was ascertained at amniocentesis performed on a 39 year old woman. The marker was found in all three primary cultures, but the frequency varied from $3 \%$ to $90 \%$ (figure A). The pregnancy continued and a normal female was delivered at term, when the marker was found with a frequency of $38 \%$ in the baby's lymphocytes. At 7 months the baby was developing normally.

Table 2 Ascertainment, chromosomal origin, and outcome in 15 cases with supernumerary marker chromosomes.

\begin{tabular}{|c|c|c|c|c|c|c|c|c|}
\hline Case & $\begin{array}{c}\text { Chromosomal } \\
\text { origin }\end{array}$ & Parental & Ascertainment & $\begin{array}{c}\text { Frequency } \\
\text { of marker } \\
(\%)\end{array}$ & Morphology & Size & Outcome & HGM $^{*}$ \\
\hline $\begin{array}{l}1 \\
2 \\
3 \\
4 \\
5 \\
6\end{array}$ & $\begin{array}{c}4 \\
4 \\
12 \\
13 / 21 \\
13 / 21 \\
13 / 21\end{array}$ & $\begin{array}{l}\text { Maternal } \\
\text { De novo } \\
\text { De novo } \\
\text { Maternal } \\
\text { De novo } \\
\text { De novo }\end{array}$ & $\begin{array}{l}\text { PND for maternal age } \\
\text { PND for maternal age } \\
\text { PND for maternal age } \\
\text { Developmental delay } \\
\text { Mental retardation } \\
\text { PND for maternal age }\end{array}$ & $\begin{array}{r}80 \\
27 \\
38 \\
100 \\
10 \\
100\end{array}$ & $\begin{array}{l}\text { V small } \\
\text { V small } \\
\text { V small } \\
\text { Bisatellited } \\
\text { Bisatellited } \\
\text { Satellited }\end{array}$ & $\begin{array}{l}<22 \\
<22 \\
<22 \\
\leqslant 22 \\
=22 \\
\leqslant 22\end{array}$ & $\begin{array}{l}\text { Normal } \\
\text { TOP } \dagger \\
\text { Normal } \\
\text { Abnormal } \\
\text { Abnormal } \\
\text { Pregnancy } \\
\text { continuing }\end{array}$ & $\begin{array}{l}\text { DD46 } \\
\text { DD68 } \\
\text { DD121 } \\
-\quad \\
\text { DD135 } \\
\text { DD503 }\end{array}$ \\
\hline $\begin{array}{r}7 \\
8 \\
9 \\
10 \\
11\end{array}$ & $\begin{array}{l}14 \\
14 \\
16 \\
19 \\
19\end{array}$ & $\begin{array}{l}\text { De novo } \\
\text { De novo } \\
\text { De novo } \\
\text { Not known } \\
\text { De novo }\end{array}$ & $\begin{array}{l}\text { Speech and developmental delay } \\
\text { PND for maternal age } \\
\text { PND for maternal age } \\
\text { Floppy baby } \\
\text { PND for maternal age }\end{array}$ & $\begin{array}{l}90 \\
60 \\
90 \\
50 \\
60\end{array}$ & $\begin{array}{l}\text { Small } \\
\text { Small } \\
\text { Small } \\
\text { Small } \\
\text { Variable }\end{array}$ & $\begin{aligned} & \leqslant 22 \\
& \leqslant 22 \\
& \leqslant 22 \\
& \sim 21 \\
& <22 \\
\& & \sim 21\end{aligned}$ & $\begin{array}{l}\text { Abnormal } \\
\text { TOP } \dagger \\
\text { Normal } \\
\text { Abnormal } \\
\text { Abnormal }\end{array}$ & $\begin{array}{l}\text { DD227 } \\
\text { DD357 } \\
\text { DD104 } \\
\text { DD549 }\end{array}$ \\
\hline $\begin{array}{l}12 \\
13 \\
14 \\
15\end{array}$ & $\begin{array}{c}22 \\
22 \\
\mathrm{Y} \\
\mathrm{NK}\end{array}$ & $\begin{array}{l}\text { De novo } \\
\text { De novo } \\
\text { De novo } \\
\text { De novo }\end{array}$ & $\begin{array}{l}\text { PND for maternal age } \\
\text { PND for maternal age } \\
\text { PND for maternal age } \\
\text { PND for maternal age }\end{array}$ & $\begin{array}{r}100 \\
100 \\
42 \\
100\end{array}$ & $\begin{array}{l}\text { Bisatellited } \\
\text { Bisatellited } \\
\text { Small } \\
\text { Small }\end{array}$ & $\begin{array}{l}\leqslant 22 \\
\leqslant 22 \\
\leqslant 22 \\
\leqslant 22\end{array}$ & $\begin{array}{l}\text { Normal } \\
\text { TOP§ } \\
\text { TOP\| } \\
\text { TOP§ }\end{array}$ & $\begin{array}{l}\text { DD347 } \\
\text { DD87 } \\
\text { DD107 } \\
\text { DD46 }\end{array}$ \\
\hline
\end{tabular}

* Depositor number at the European Cell \& Culture Collection, Porton Down, Salisbury SP4 0JG, UK. 

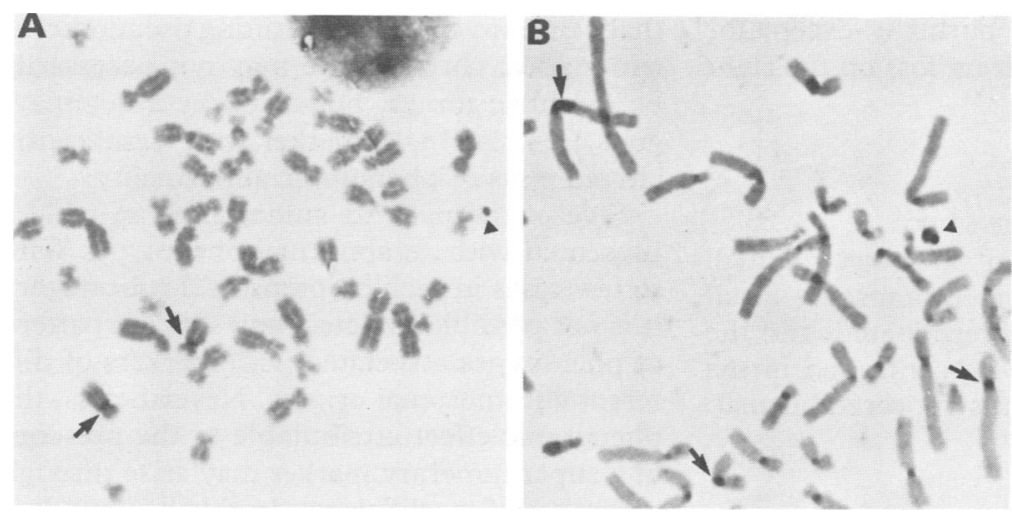

(A) Immunoperoxidase staining of a metaphase from case 3 (mar 12) after in situ hybridisation with $p \alpha 12 H 8$ shows the very small marker (arrowhead) and both normal chromosome 12 centromeres (arrows) labelled. (B) An example of the dicentric marker seen in $13 \%$ of the metaphases examined from case 11 (mar 19-partial metaphase). The marker (arrowhead) shows two discrete areas of diaminobenzidene precipitation after immunoperoxidase detection after in situ hybridisation with the D5/1/19Z1 probe. Normal 1, 5, and 19 centromeres (arrows) show distinct brown staining in contrast to the magenta/blue $C$ banding observed on some other chromosomes. slightly downward sloping eyes, and hypermobile joints. A marker, smaller than a chromosome 22 , was found in $90 \%$ of lymphocytes studied.

CASE 8: 46,XY/47,XY, + MAR(14) DE NOVO

Chorionic villus sampling from a 41 year old woman showed a small $(\leqslant 22)$ marker chromosome in $60 \%$ of cells derived from long term cultures. The pregnancy was terminated at the end of the first trimester and therefore no morphological evaluation was possible.

CASE 9: $46, \mathrm{XY} / 47, \mathrm{XY},+\mathrm{MAR}(16) \mathrm{DE}$ NOVO

Amniocentesis on a 43 year old woman showed a small $(\leqslant 22)$ marker chromosome in $90 \%$ of cells examined. The pregnancy continued to term and at 17 months the baby was developing normally.

CASE 10: $46, \mathrm{XX} / 47, \mathrm{XX},+\mathrm{MAR}(19)$ NOT KNOWN This patient was referred at the age of 3 weeks for failure to thrive, severe floppiness, and pneumonia. A small $(\leqslant 22)$ marker seen in half of the peripheral lymphocytes examined was positive for the $\mathrm{D} 5 / 1 / 19 \mathrm{Z} 1$ probe, and by a series of other hybridisations all centromeres except 19 were excluded as the origin. lymphocytes and had required special schooling, particularly with reading and writing. Both the proband and his mother had strikingly similar round facial features with brachydactyly. The maternal grandmother also carried the marker in $1 \%$ of lymphocytes but was intellectually and phenotypically normal. The in situ hybridisation diagnosis of the marker's origin was performed on the proband's lymphocytes.

CASE 5: $46, \mathrm{XY} / 47, \mathrm{XY},+\operatorname{MAR}(13 / 21)$ DE NOVO

The patient was referred at the age of 41 for mild mental retardation. A bisatellited marker, the size of a chromosome 22, was found in $10 \%$ of peripheral blood lymphocytes. The patient had attended a school for children with special educational needs and on examination was noted to have a rounded face, short stubby fingers, and slightly lax joints but was otherwise normal in appearance.

CASE 6: 47,XX, $+\operatorname{MAR}(13 / 21)$ DE NOVO

Amniocentesis on a 41 year old woman showed a small $(\leqslant 22)$ satellited marker chromosome in all cells examined. The pregnancy is continuing to term.

CASE 7: $46, \mathrm{XY} / 47, \mathrm{XY},+\operatorname{MAR}(14) \mathrm{DE}$ NOVO

This patient was first examined cytogenetically at 3 years of age because of delayed speech, and on re-examination eight months later his overall development was around 3 years, but still below this for speech. At birth he was noted to have a left undescended testicle, bilateral preauricular sinuses, bifid tongue, wide set and
CASE 11: 46,XY/47,XY, + MAR $_{1}(19) / 47, \mathrm{XY},+\mathrm{MAR}_{2}(19) /$ $47, \mathrm{XY},+\mathrm{MAR}_{3}$ (?) $\mathrm{DE}$ NOVO

This patient's marker chromosome was originally discovered in $60 \%$ of the cells examined from long term cultures after a CVS biopsy from his 36 year old mother. At term the marker was found with the same frequency in the proband's peripheral blood. He was referred to this laboratory for in situ studies at the age of 14 months at which stage he was found to have a large head (on the 98th centile), frontal bossing, epicanthic folds, hypotonia, and developmental delay. In situ hybridisation studies showed four distinguishable cell populations. Forty percent of cells were normal $(46, X Y) ; 27 \%$ contained a small $(\leqslant 22)$ marker with a single $\mathrm{D} 5 / 1 / 19 \mathrm{Z} 1$ centromeric signal; $13 \%$ had a dicentric marker approximately the size of a chromosome 21 and positive for two copies of D5/1/19Z1 (figure B); and the remaining $20 \%$ of cells contained a small marker $(\leqslant 22)$ which failed to show a signal with any of the probes in the library. Thirty cells were examined from each hybridisation in order to exclude the possibility that the negative signal in the unlabelled markers was a technical artefact.

CASE 12: 46,XY/47,XY, + MAR(22) DE NOVO a small $(\leqslant 22)$ bisatellited marker in all amniocyte cells examined. At birth, the presence of the marker was confirmed in the baby's lymphocytes but with a frequency of $80 \%$. The in situ studies were carried out on the proband's lymphocyte chromosomes. At the age of 5 Amniocentesis on a 39 year old woman showed 
years he was developing normally except for slight high frequency hearing loss on the right side.

CASE 13: 47, $\mathrm{XX},+\operatorname{MAR}(22)$ DE NOVO Amniocentesis at the age of $\mathbf{3 5}$ showed a small $(\leqslant 22)$ bisatellited marker chromosome in all cells. The pregnancy was terminated, and the presence of the marker was confirmed in the fetus. At necropsy the fetus appeared normal.

CASE 14: $45, \mathrm{X} / 46, \mathrm{X},+\operatorname{MAR}(\mathrm{Y}) \mathrm{DE}$ NOVO

Amniocentesis on a 39 year old woman showed a mosaic karyotype with a small $(\leqslant 22)$ marker in $42 \%$ of amniocytes examined. The mar $(Y)$ was ring like in appearance and gave two distinct signals with both the DYZ3 (centromere) and DYZ5 (Yp heterochromatin) probes. The pregnancy was terminated and at necropsy the fetus was found to be a hermaphrodite with a short penis, no uterus, and with an ovary on the left side and a testis on the right.

CASE 15: 47,XX, + MAR(?ORIGIN) DE NOVO Amniocentesis on a 36 year old woman showed the presence of a small $(\leqslant 22)$ marker in all cells examined. In situ hybridisation was performed with all the probes in the library but no signal was seen from the marker in the 10 cells examined after each hybridisation. The pregnancy was terminated and the necropsy report indicated an apparently normal fetus with no major congenital abnormalities.

\section{Discussion}

The phenotypic consequences of a supernumerary marker chromosome remain difficult to evaluate despite a number of conventional cytogenetic staining methods. Some markers, for example $i(12 p)$ and $i(18 p)$, can be characterised with conventional cytogenetic methods and these have well defined abnormal phenotypic consequences. ${ }^{1718}$ Furthermore, distamycin-DAPI staining techniques are used to identify chromosome 15 derived markers. Markers involving duplications of 15 pter $\rightarrow$ q21 are associated with varying degrees of mental handicap..$^{5-7}$ However, the use of distamycin-DAPI alone for marker diagnostic purposes should be interpreted with caution in the light of two recent studies. In the first, Smeets et al ${ }^{19}$ showed that approximately $6 \%$ of normal subjects have three copies of $15 p$ (that is, the region defined by the probe D15Z1 and distamycin-DAPI). In these cases, two signals were seen on the normal chromosomes 15 and a third on either a $13 p$ or $14 \mathrm{p}$. A recent study by Stergianou et $a l^{20}$ repeated these experiments but in addition used an alphoid chromosome 15 centromere specific probe (pTRA-25). ${ }^{21}$ In all cases with three $15 p$ distamycin-DAPI signals only two 15 centromere signals were observed, always from the normal 15 homologues. These results suggest that a distamycin-DAPI staining pseudodicentric marker chromosome may not necessarily be dicentric for 15, but could be a heterozygous $13 / 15$ or $14 / 15$ marker with significantly altered risks of phenotypic abnormality.

Five of the patients summarised in table 2 presented with an abnormal phenotype. With so few cases in each chromosomal subcategory it is not possible to detect any striking pattern of phenotypes associated with markers of different chromosomal origins. Nevertheless, the phenotypic effect attributable to the presence of a supernumerary marker may arise through a number of mechanisms. In this context, it is interesting that case 7 in this study and a case recently reported by Temple et $a l^{2}$ both had undescended testes. Temple et $a^{22}$ showed that their proband was uniparentally disomic for the maternal chromosomes 14 . The supernumerary marker(14) in case 7 of this study may also be maternal in origin resulting in an excess of maternally derived genes for the pericentric region of chromosome 14. Marker chromosomes may, therefore, cause an abnormal phenotype not only by dosage effects, but also because of chromosome specific imprinting resulting in an imbalance between the normal ratio of maternal and paternal genes. Indeed, such an effect is well established in some patients with markers derived from chromosome 15 who have the Prader-Willi syndrome. $^{7}$

Six of the remaining 10 cases ascertained through prenatal diagnosis had normal phenotypes. In case 3 , the chromosomal assignment of the marker(12) was made postnatally. With the known association of Pallister-Killian syndrome and the tetrasomy $12 \mathrm{p}$ marker chromosome,,$^{17}$ it is difficult to assess retrospectively how the chromosomal assignment of the marker(12) would have affected the risk estimates if the in situ results had been known prenatally. The marker(12) in this case suggests that triplication (or quadruplication) of the pericentromeric region of chromosome 12 alone is not sufficient to produce the Pallister-Killian phenotype.

It is interesting to note that cases 12 and 13, both of which had karyotypes with non-mosaic bisatellited and dicentric marker(22) chromosomes, were phenotypically normal. Bisatellited markers thought to be derived from chromosome 22pter $\rightarrow$ p11 are associated with the 'cat eye syndrome', ${ }^{23}$ which has a wide spectrum of associated malformations varying from mild to very severe. However, because of the markers' small size and indistinct staining characteristics, their derivation from chromosome 22 remains conjectural. ${ }^{23}$ We have recently used in situ hybridisation with the chromosome 22 centromere specific probe p190.22 to show that the marker in a case presenting with several of the classical features of cat eye syndrome, that is, anal atresia, accessory auricles, preauricular sinuses, and slight dysmorphic features, was indeed a dicentric marker(22) (Howard and Crolla, unpublished results). Cases 12 and 13 in this study may, therefore, represent extremely 
mild examples of cat eye syndrome. Alternatively, the parental origin of an additional chromosome 22 marker may affect the phenotype. It is known that persons who have maternal uniparental disomy for chromosome 22 are phenotypically normal. ${ }^{24}{ }^{25}$ However, the phenotype of persons with paternal uniparental disomy 22 is unknown. It is conceivable that subjects with a maternally derived marker 22 may be asymptomatic but those with a paternally derived marker 22 will manifest the cat eye syndrome.

The stable retention, even as low grade mosaic cell lines, of markers suggests that they have functional kinetochores, but whether they invariably retain intact alphoid sequences is open to question in the light of the cases described in the present paper (cases 11 and 15) and that studied by Callen et al $^{14}$ (case 2). Although these markers were negative for all the centromere and pericentromeric probes, they were stable within their respective karyotypes.

Knowledge of the chromosomal origin of a supernumerary marker chromosome may provide significant prognostic information once larger numbers of patient/karyotype correlations have been described. However, other factors such as imprinting and dosage effects may also have to be known before an accurate risk estimate for any given de novo marker can be given. ${ }^{26} \mathrm{~A}$ first step towards unravelling these complex events remains the chromosomal origin of the supernumerary markers.

We are very grateful to Drs $\mathbf{P}$ Devilee, $\mathrm{H}$ Willard, M Rocchi, P Goodfellow, U Muller, and $\mathrm{K}$ Choo for the generous gifts of the probes used in this study. We acknowledge the help of the referring clinicians of the Wessex Regional Health Authority for their clinical summaries and for the cytogenetics staff of the Wessex Regional Genetics Laboratory for their technical help.

1 Hsu LYF. Prenatal diagnosis of chromosome abnormalities. In: Milunsky A, ed. Genetic disorders and the fetus. Diagnosis, prevention and treatment. New York: Plenum Press,

2 Jacobs PA. The role of chromosome abnormalities in reproductive failure. Reprod Nutr Dev 1990;suppl 1:63s-74s.

3 Hook EB, Schreinemachers DM, Willey AM, Cross PK. Rates of mutant structural chromosome rearrangements in human fetuses: data from prenatal cytogenetic studies and associations with maternal age and parental mutagen exposure. Am F Hum Genet 1983;35:96-109.

4 Warburton D. De novo balanced chromosome rearrangements and extra marker chromosomes identified at prenatal diagnosis: clinical significance and distribution of breakpoints. Am $\mathcal{F}$ Hum Genet 1991;49:995-1013.
5 Buckton KE, Spowart G, Newton MS, Evans HJ. Forty four probands with an additional "marker" chromosome. Hum Genet 1985;69:353-70.

6 Mohandas T, Canning N, Chu W, Passage MB, Anderson CE, Kaback MM. Marker chromosomes: cytogenetic characterization and implications for prenatal diagnosis. Am $\mathcal{F}$ Med Genet 1985;20:361-8.

7 Maraschio P, Cuoco C, Gimelli G, Zuffardi O, Tiepolo L. Origin and clinical significance of inv dup(15). In: The cytogenetics of mammalian autosomal rearrangements. New
York: Alan R Liss, 1988:615.

8 Willard HF, Waye JS. Hierarchical order in chromosomespecific human alpha satellite DNA. Trends Genet 1987;3:192.

9 Vogt P. Potential genetic functions of tandem repeated DNA sequence blocks in the human genome are based on a highly conserved "chromatin folding code". Hum Genet 1990;84:301-6.

10 Crolla JA, Llerena JC. A mosaic 45,X/46,X,r(?) karyotype investigated with $\mathrm{X}$ and $\mathrm{Y}$ centromere-specific probes using a non-autoradiographic in situ hybridization technique. Hum Genet 1988;81:81-4.

11 Cooper C, Crolla JA, Laister C, Johnston DI, Cooke P. An investigation of ring and dicentric chromosomes found in three Turner's syndrome patients using DNA analysis and in situ hybridisation with $X$ and $Y$ chromosome specific probes. $\mathcal{f}$ Med Genet 1991;28:6-9.

12 Jacobs PA, Betts PR, Cockwell AE, et al. A cytogenetic and molecular reappraisal of a series of patients with Turner's molecular reappraisal of a series of patients with

13 Callen DF, Ringenbergs ML, Fowler JCS, Freemantle J, Haan EA. Small marker chromosomes in man: origin from pericentric heterochromatin of chromosomes 1, 9, and 16. F Med Genet 1990;27:155-9.

14 Callen DF, Eyre HJ, Ringenbergs $M L$, Freemantle CJ, Woodroffe P, Haan EA. Chromosomal origin of small ring marker chromosomes in man: characterization by molecular genetics. Am ₹ Hum Genet 1991;48:769-82.

15 Crolla JA, Gilgenkrantz S, deGrouchy J, Kajii T, Bobrow $M$. Incontinentia pigmenti and $X$-autosome translocations: non-isotopic in situ hybridization with an $\mathrm{X}$-centromere specific probe (pSV2X5) reveals a possible Xcentromere breakpoint in one of five published cases. Hum Genet 1989;81:269-72.

16 Kievits T, Dauwerse JG, Wiegant J, et al. Rapid subchromosomal localization of cosmids by nonradioactive in situ hybridization. Cytogenet Cell Genet 1990;53:134-6.

17 Schinzel A. Tetrasomy 12p (Pallister-Killian syndrome). $\mathcal{f}$ Med Genet 1991;28:122-5.

18 Singer TS, Kohn G, Yatziv S. Tetrasomy-18p in a child with trisomy-18 phenotype-brief clinical report. $A m \mathcal{F}$ Med Genet 1990;36:144-7.

19 Smeets DFCM, Merkx GFM, Hopman AHM. Frequent occurrence of translocations of the short arm of chromosome-15 to other D-group chromosomes. Hum Genet 1991;87:45-8.

20 Stergianou $\mathrm{K}$, Gould $\mathrm{CP}$, Waters JJ, Hulten $\mathrm{M}$. High population incidence of the $15 \mathrm{p}$ marker $\mathrm{D} 15 \mathrm{Z} 1$ mapping
to the short arm of one homologue 14. Hum Genet 1992;88:364.

21 Choo KH, Earle E, Vissel B, Filby RG. Identification of two distinct subfamilies of alpha satellite DNA that are highly specific for human chromosome 15. Genomics 1990;7:143-51.

22 Temple IK, Cockwell A, Hassold T, Pettay D, Jacobs P Maternal uniparental disomy for chromosome 14. $\mathcal{J}$ Med Genet 1991;28:511-4.

23 Schinzel A, Schmid W, Fraccaro M, et al. The "cat eye syndrome": dicentric small marker chromosomes probably derived from a no 22 (tetrasomy 22pter- $>$ q11) associated with a characteristic phenotype. Hum Genet $1981 ; 57: 148-58$

24 Palmer CG, Schwartz S, Hodes ME. Transmission of a balanced homologous $t(22 \mathrm{q} ; 22 \mathrm{q})$ translocation from mother to normal daughter. Clin Genet 1980;17:418-22.

25 Kirkels VGHJ, Hustink TWJ, Scheres JMJC. Habitua abortion and translocation $(22 \mathrm{q} ; 22 \mathrm{q})$ : unexpected transmission from a mother to her phenotypically normal daughter. Clin Genet 1980;18:456-61.

26 Dahoun-Hadorn S, DeLozier-Blanchet C. Reflections on small supernumerary (marker) chromosomes: could imprinting and isodisomy play a role in the phenotypic expression of hyperdiploidy? Ann Genet (Paris) 1990;33:241-2. 